\title{
O QUE A ARTE DÁ A PENSAR: PROVOCAÇÕES DELEUZIANAS A ALUNOS DA REDE MUNICIPAL DE SÃO PAULO EM MEIO À PANDEMIA DO CORONAVÍRUS E O QUE ELES TÊM A DIZER SOBRE ISSO
}

\author{
HOW ART MAKE US THINK: DELEUZIAN PROVOCATIONS TO STUDENTS FROM \\ THE SÃO PAULO MUNICIPAL NETWORK IN THE CORONAVIRUS PANDEMIC AND \\ WHAT THEY HAVE TO SAY ABOUT IT
}

\author{
Lilian dos Santos Silva ${ }^{1}$ \\ Lydia Minhoto Cintra ${ }^{2}$ \\ Glaucia Ribeiro Felipe $\mathrm{Cabral}^{3}$
}

\begin{abstract}
Resumo: Este artigo apresenta uma proposta delineada a partir do pensamento de Gilles Deleuze, que foi lançada a 150 alunos de $1^{\circ}$ a $9^{\circ}$ ano, de 21 salas de aula, da Escola Municipal Comandante Gastão Moutinho, localizada na capital paulista. Desenvolvida a distância, durante a pandemia do novo coronavírus em 2020, a atividade privilegia experimentações com arte e com uma filosofia da imanência. Elegemos quatro ilustrações do quadrinista Rafael Sica para armar uma ambiência e promover algumas provocações. Considerando-se alunos e obras como forças em contato, instauraram-se encontros que permitiram abrir caminhos a afecções, a modos de sentir e ao ato de pensar, pela perspectiva deleuziana. Sem requisitar quaisquer interpretações predeterminadas, tencionamos o que esses alunos têm a dizer acerca do que a arte deu a eles a pensar. Neste artigo, detalhamos esta proposta para, na sequência, mostrar o que os estudantes produziram e tecer algumas análises.
\end{abstract}

Palavras-chave: Deleuze; educação; alunos.

\begin{abstract}
This article presents a proposal outlined from the thought of Gilles Deleuze, which was launched to 150 students from $1^{\circ}$ to $9^{\circ}$ grade, from 21 classrooms, at the Municipal School Comandante Gastão Moutinho, located in the capital of the State of São Paulo. Developed remotely, during the new coronavirus pandemic in 2020, the activity favours experimentations with art and with a philosophy of immanence. We chose four illustrations by the artist Rafael Sica to set an ambience and to promote some provocations. Considering students and works as forces in contact, meetings were established that opened way to affections, ways of feeling and the act of thinking, from the Deleuzian perspective. Without requiring any predetermined interpretations, we intend to see what students have to say about how art make them think. In this article, we detail this proposal to, next, show what the students produced and make some analyzes.
\end{abstract}

Keywords: Deleuze; education; pupils.

\section{Notas iniciais}

De repente, de uma hora para outra, no início do ano letivo de 2020, a necessidade irrevogável de manter distanciamento social impôs o fechamento das escolas no país; deflagravase a maior crise sanitária de nossos tempos. A determinação restritiva, implantada para evitar o contágio e salvar vidas - uma medida dentre outras, como o uso de máscaras e de álcool gel -, suspendeu os encontros cotidianos de professores e alunos nas aulas presenciais. Disseminando

\footnotetext{
${ }^{1}$ Faculdade de Educação da Universidade de São Paulo, São Paulo, São Paulo, Brasil.

${ }^{2}$ Universidade de São Paulo, São Paulo, São Paulo, Brasil.

${ }^{3}$ Universidade de São Paulo, São Paulo, São Paulo, Brasil.
} 
um arrastão, a pandemia da Covid-19 instalou uma conjuntura de insegurança, temor e incerteza, que impôs outros modos de viver e, no que tange à educação, diversos desafios, sendo o distanciamento um deles. Não frequentar as escolas disparou uma série de efeitos para as forças em jogo: alunos, professores, funcionários, pais, responsáveis, familiares etc.

O deslocamento da sala de aula para as plataformas virtuais modulou o ensino e o trabalho pedagógico, demandando ajustes, recomposições e rearranjos. Nas redes públicas, um dos principais gargalos dessa mudança concentra-se na dificuldade que parte dos alunos enfrenta para conseguir acessar essa via de contato e participar dessa dinâmica. Tal entrave se dá por vários motivos: falta de aparelhos eletrônicos, de conexão de internet, de ambiente adequado aos estudos; além de que, muitas vezes, uma parcela ainda se depara com contextos familiares desfavoráveis para acompanhar aulas e realizar atividades. Em janeiro de 2021, quando este texto é escrito, às vésperas da pandemia completar um ano no Brasil, continuamos a lidar com esses impasses; foi e ainda é preciso bancar relações a distância, defrontá-las e contorná-las, algo inédito.

Nos fluxos da circunstância pandêmica - anteriormente impensável -, frente aos percalços e, sobretudo, ao distanciamento, reúnem-se esforços. Atravessados e pressionados por essa situaçãolimite, professoras e professores - como nós - foram impelidos a encontrar saídas, respiros, linhas de fuga (DELEUZE; PARNET, 1998), tramando meios de manejar, na prática, tal contingência. A partir do pensamento de Gilles Deleuze, produzimos uma atividade que visa fomentar afecções, modos de sentir e o ato de pensar - fulcrais nesse período tão adverso. Para tanto, instauramos um território por meio de uma ambiência com a arte e promovemos algumas provocações.

A proposta foi lançada a 150 alunos de $1^{\circ}$ a $9^{\circ}$ ano, de 21 salas de aula da Escola Municipal Comandante Gastão Moutinho, localizada na zona norte da capital paulista, onde duas de nós lecionamos. Os estudantes participantes tiveram acesso à atividade nas disciplinas Sala de Leitura e Arte e a desenvolveram de julho a setembro de 2020, sendo compartilhada - e as devolutivas, recebidas - por meio da plataforma Google Sala de Aula, via de comunicação oficial da rede municipal de São Paulo neste período.

Apresentamos o percurso deste trabalho neste artigo, que se divide em duas partes: I) proposta e II) o que os alunos têm a dizer. Primeiro, delineamos a atividade, que privilegia experimentações com arte e com uma filosofia da imanência, para depois exibir efeitos de sua execução. Nesta segunda parte, acionamos produções dos estudantes que registram o que eles têm a dizer sobre as provocações da iniciativa, tendo em vista a ambiência instaurada, e o que a arte deu a eles a pensar. Estas proposições dos participantes movem esta produção escrita. Por isso, mobilizamos muitas delas a fim de abrir espaço ao que os alunos nos trazem, o que também permite tecer algumas análises. Acrescentamos, por fim, alguns bastidores que tratam da laboração da iniciativa na trilha de uma filosofia da imanência.

\section{Proposta}

A atividade possui uma orientação simples e objetiva. Tomamos como disparadores quatro ilustrações do livro Triste (2019), do quadrinista Rafael Sica. Enviamos as obras aos alunos e pedimos que eles as observassem, despendendo o tempo que fosse necessário para isso. Sem fornecer nem requisitar quaisquer direcionamentos interpretativos - no sentido do que as imagens querem dizer -, insistimos nesse contato sugerindo apenas que deixassem que as ilustrações falassem com eles. Isso para, porventura, poderem perscrutar o que elas teriam a dizer, caso lhes dissessem alguma coisa. Convidamos, na sequência, ao encontro com tais obras. 


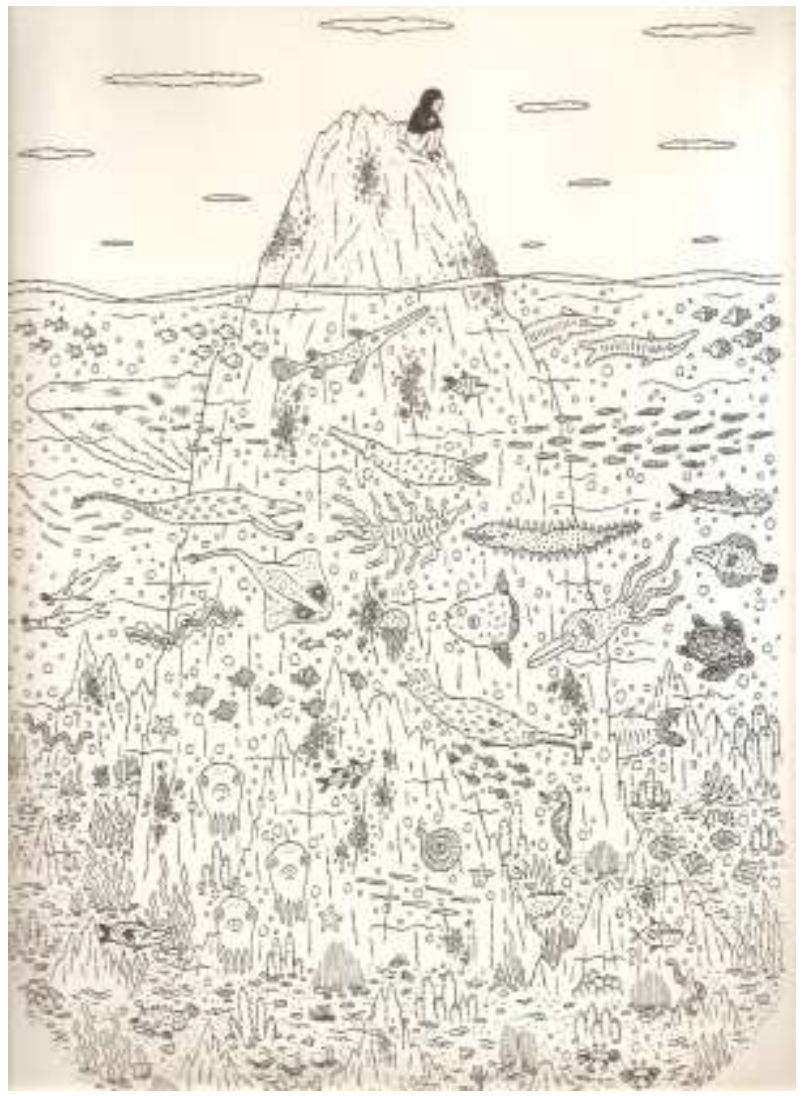

Figura 1 - Fonte: SICA, Rafael. Triste. São Paulo: Lote 42, 2019.

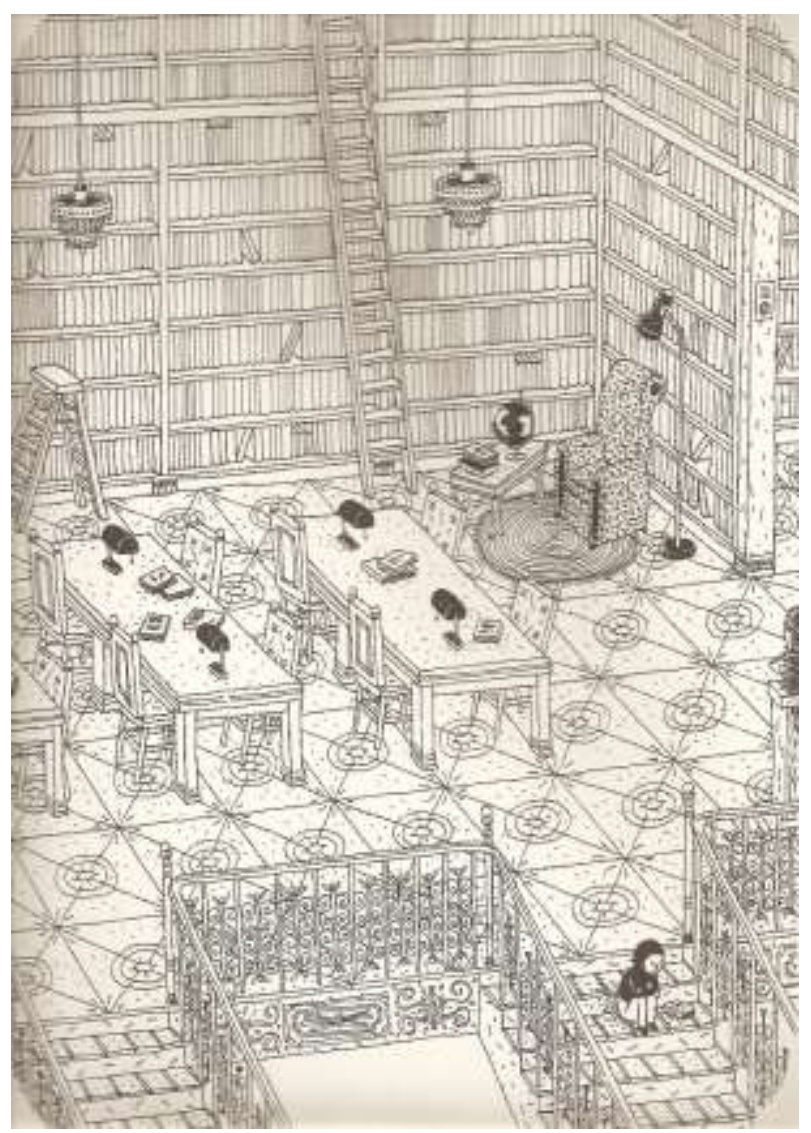


Figura 2 - Fonte: SICA, Rafael. Triste. São Paulo: Lote 42, 2019.

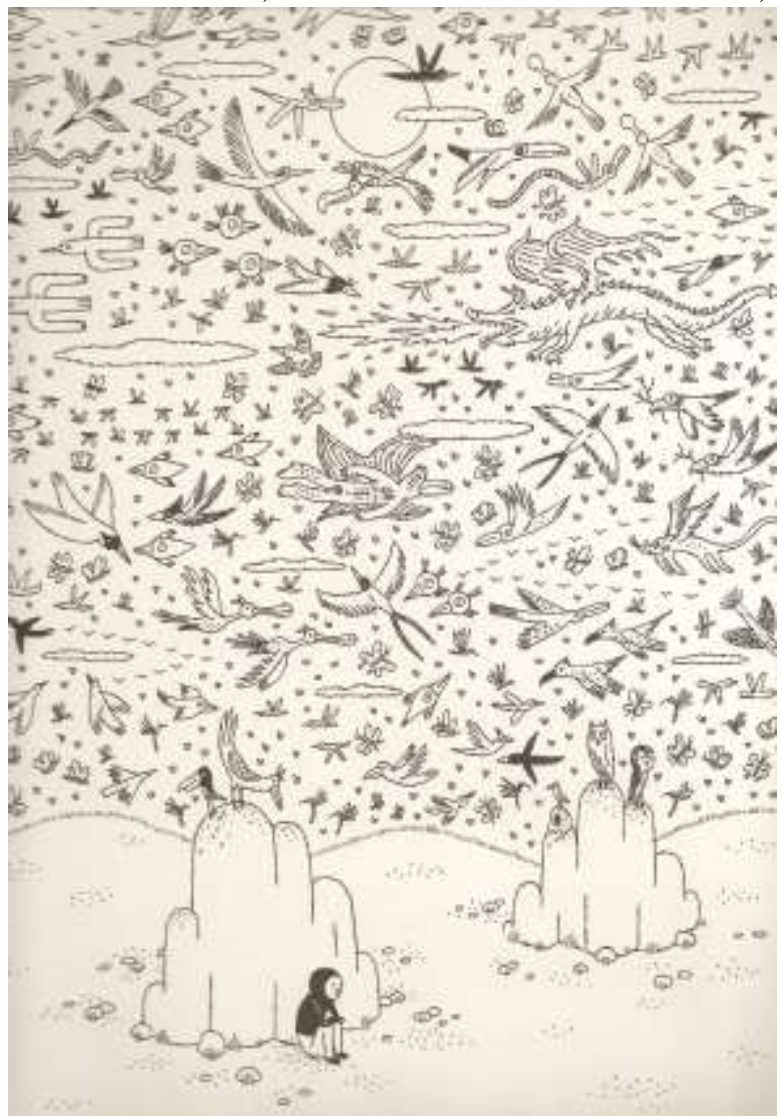

Figura 3 - Fonte: SICA, Rafael. Triste. São Paulo: Lote 42, 2019.

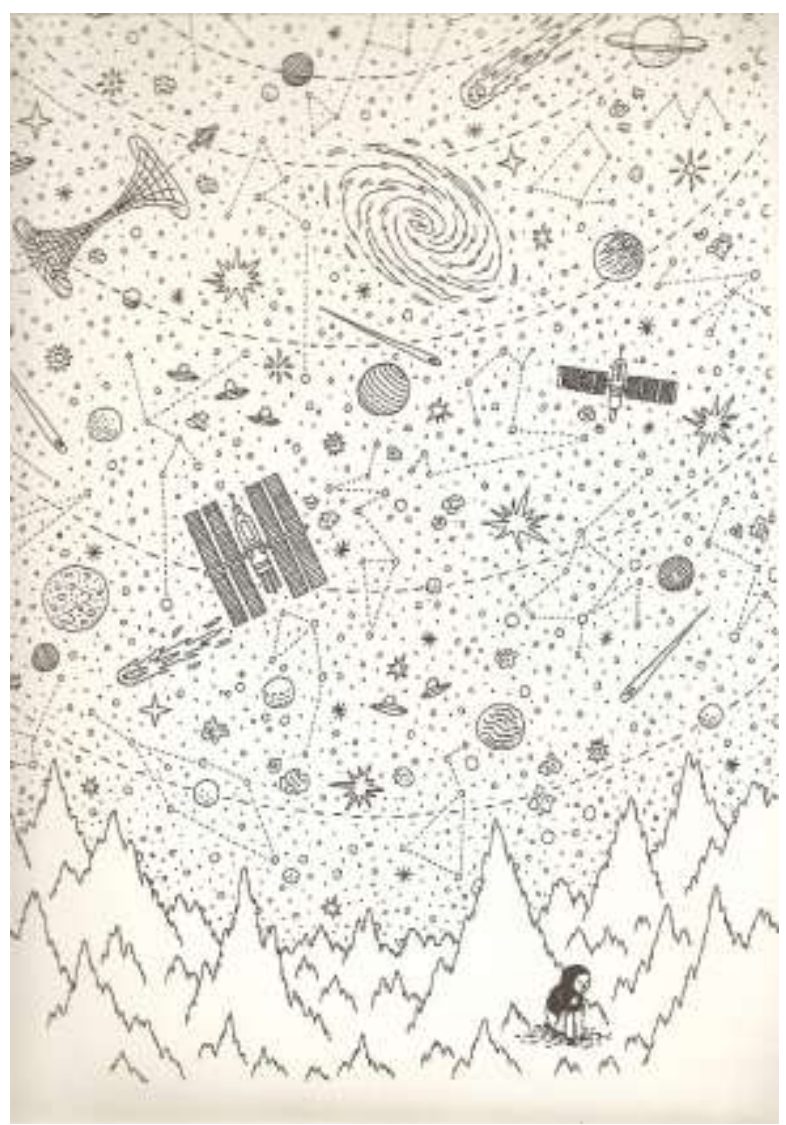


Figura 4 - Fonte: SICA, Rafael. Triste. São Paulo: Lote 42, 2019.

Como os alunos experimentaram um contato com as obras, referimo-nos a esse encontro como uma experimentação. Ao solicitarmos uma parada e a dedicação de um tempo para as ilustrações, intentamos instaurar uma ambiência com esse conjunto. Não se trata de focalizar apenas uma imagem, mas quatro que, juntas, compõem um território. Cada uma tem suas peculiaridades, assim como há fatores que se repetem em todas elas. Ao reuni-las e promover esta experimentação, ficamos à espreita a fim de ver o que saltava em meio a essas repetições e particularidades.

Não oferecemos, propositadamente, nenhuma descrição das ilustrações. Como, aqui, nosso objetivo consiste em desdobrar a atividade e trata-se de um texto expositivo, efetuamos, neste caso, uma breve tomada das obras. As quatro imagens trazem um mesmo personagem, sem traços muito definidos, sentado, sozinho, em locais em que uma série de elementos habitam a paisagem. Dessa forma, ele se insere em lugares povoados que acenam universos em profusão, os quais parece ignorar.

Na primeira ilustração (figura 1), o personagem está em uma pequenina ilha e, logo abaixo, no mar, vislumbra-se uma abundante movimentação de peixes, entre outros animais. Na segunda (figura 2), ele está em uma biblioteca repleta de livros. Na terceira (figura 3), está em um local ao ar livre, com uma agitação de pássaros no céu. Na quarta (figura 4), ele também está ao ar livre, circundado por planetas, satélites e outros elementos que dançam pelo espaço sideral.

Após a experimentação, propusemos uma abordagem mais ampla, de início, seguida de encaminhamentos mais diretivos: 1) convidamos os alunos a relatar o que as quatro ilustrações de Rafael Sica davam a pensar. Avançando, os interpelamos, questionando: 2) "quais sensações e modos de sentir as ilustrações produzem?"4; e 3) "se as imagens fizessem uma pergunta, qual pergunta seria?". Para termos acesso às trajetórias urdidas por essas três veredas, solicitamos que eles fizessem os registros de suas proposições e nos enviassem.

A atividade completa contém mais perguntas. Contudo, as provocações supracitadas dão conta do que procuramos incitar. Devido à amplitude de faixas etárias e de fases de ensino com a qual trabalhamos, foram articuladas, a partir desta proposta-base, quatro formas de disposição, quais sejam, 1) para ciclo de alfabetização $-1^{\circ}, 2^{\circ}$ e $3^{\circ}$ anos, 2) para $4^{\circ}$ e $5^{\circ}$ anos, 3) para $6^{\circ}$ e $7^{\circ}$ anos e 4) para $8^{\circ}$ e $9^{\circ}$ anos, variações essas que buscaram talhar a iniciativa de acordo com o gradiente de idades e de anos letivos dos participantes ${ }^{5}$.

As provocações da proposta partem de uma filosofia da imanência ancorada no pensamento de Deleuze (2002a) ${ }^{6}$. Tal viés teórico opõe-se ao platonismo, à recognição e à representação, e defende que o importante não é fazer como um modelo, repetir, mas criar. E na trilha deleuziana, não importam sujeitos e objetos; o que há são forças que, ao se encontrarem, podem se afetar, se contagiar, produzir efeitos e outras forças.

Tomamos, então, alunos e obras como forças, e, assim, não se poderia prenunciar o que viria desta atividade, todavia apostamos nisso. Buscamos arriscar encontros de forças e, a partir daí, efeitos imponderáveis, impossíveis de se prever a priori, tal como ocorre no campo educacional, de maneira mais ampla.

Acompanhando essa montagem da proposta, as perguntas que fizemos prescindem de gabaritos ou de cálculos de respostas prévias aceitáveis. Não projetamos um mínimo denominador comum nem programamos que os alunos alcançassem qualquer ponto de chegada. Pelo contrário, enaltecemos a pluralidade de proposições na tentativa de, talvez, propiciar

\footnotetext{
${ }^{4}$ Não fizemos a pergunta aos alunos utilizando exatamente o termo "modos de sentir", que é uma palavra-conceito do âmbito de nosso referencial teórico. Valemo-nos de um vocabulário - ou de um "modo de dizer" - mais próximo a eles. ${ }^{5}$ A atividade contou também com uma segunda fase, na qual propusemos aos alunos a audição de uma música e os convidamos a produzir desenhos e vídeos acerca dessa outra experimentação (em continuidade à primeira).

${ }^{6}$ e também de Deleuze em companhia de Félix Guattari (2010, 2011, 2012). Enfatizamos, no entanto, neste artigo, "provocações deleuzianas" conforme os desdobramentos de análises que faremos doravante.
} 
acionamentos sensíveis. Ao demandar como se passou cada encontro, a proposta não enseja colecionar repetições ou que os alunos tenham as mesmas experimentações, mas trajetos singulares, impensáveis. Buscamos garantir que a iniciativa tivesse essa abertura.

No mais, a despeito de uma possível apreensão mais imediata, relacionada ao livro intitularse Triste, não oferecemos, de largada, essa informação. Procedemos assim para não vincular o título como um índice ou uma legenda das ilustrações; apenas o revelamos aos alunos após a atividade já ter sido realizada. Suspendemos temporariamente o fornecimento desta referência, de forma estratégica, pois suspeitávamos que os efeitos dos encontros de forças entre os alunos e as obras poderiam transtornar essa aderência; para tanto, optamos por ocultar o nome Triste.

\section{O que os alunos têm a dizer}

Após receber e reunir as produções dos alunos, nos debruçamos sobre esse arquivo para analisá-lo. Com isso, nesta segunda parte do artigo, referente à apresentação de resultados a partir dos dados obtidos, não visamos levantar estudos quantitativos das respostas nem dar conta de tudo o que foi dito. Também não acionamos as falas dividindo-as por ano em que os alunos estudam. Tomamos as devolutivas como um todo a fim de explorar nelas apreensões que incidem deslocamentos, atravessamentos e ultrapassagens. Represamos, assim, proposições que concentram percursos de pensamentos e modos de sentir.

Conforme esse enfoque, selecionamos falas e as organizamos em quatro tópicos: a) entradas mais acionadas, b) sensações e modos de sentir, c) percursos de pensamentos e modos de sentir, d) proposição de perguntas. Tais recortes nos permitem tecer breves análises, alinhavando as produções ao referencial teórico mobilizado. A fim de abarcar um maior número de falas, em vez de inseri-las na íntegra, trazemos os trechos mais pungentes de cada uma, os quais são creditados, para resguardar os participantes, com a letra inicial do primeiro nome e o ano em que estuda.

\section{a) Entradas mais acionadas}

Este primeiro tópico introduz uma ambientação do arquivo reunido. Examinando as falas dos alunos sob o aspecto de entradas acionadas, sobressai um acúmulo de apreensões. Em resposta ao que o conjunto das obras dá a pensar, temos: "me lembra do quão bom é ficar sozinho" (A., $8^{\circ}$ a.), "as imagens me passaram um pensamento de solidão em um lugar tão vago e cheio de coisas para explorar" (N., $9^{\circ}$ a.), "fazem pensar que mesmo se tivesse sozinho no mundo, ainda não estaria completamente sozinho" (B., $9^{\circ}$ a.), "é como se ele ${ }^{7}$ estivesse se preparando para o mundo porque tem tanta coisa para ele explorar, se aventurar, para ele não se sentir sozinho, mas ele busca sempre a sua solidão" (B., $9^{\circ}$ a.).

À vista de proposições como essas, a solidão e o fato de o personagem estar sozinho irrompem como apontamentos a partir dos quais se fazem conexões, face à instauração da ambiência das obras. Começamos a apresentar os efeitos desta proposta por essa marcação porque, ainda que ela tangencie um indicativo mais iminente, esta via cinge parte dos variados modos de sentir relatados, decorrentes das experimentações.

Em duas variações da proposta-base da atividade, perguntamos, mais especificamente, o que os alunos diriam ao personagem. Duas alunas e um aluno pontuam, respectivamente: "não fica triste, amigo. Estou aqui com você, vamos brincar" (A., $1^{\circ} \mathrm{a}$.), "queria ser um passarinho pra brincar junto... Vamos brincar o dia inteiro" (E., 1ª.), "vamos ler um livro" (M., $3^{\circ} \mathrm{a}$.). Dando um nome ao personagem, outro aluno afirma: "Roberto, agora você não está mais

\footnotetext{
${ }^{7}$ Os estudantes referem-se ao personagem de diversas formas, no feminino e no masculino.
} 
sozinho" (M., $3^{\circ}$ a.), ao passo que mais uma aluna anuncia: "tem muitos livros para não se sentir só" (V., $1^{\circ} \mathrm{a}$.). Na esteira das entradas supracitadas, notam-se, nessas incursões, investidas de aproximação e de interlocução e o oferecimento de companhia.

Ainda que despontem em menor número, duas outras entradas merecem menção: considerações sobre isolamento, o que abarca notadamente a conjuntura pandêmica, e sobre o uso de tecnologia. Inserimos, a seguir, duas proposições referentes a cada uma delas (que respondem ao que o conjunto das obras faz pensar). "Essas imagens me fazem pensar em tudo que estamos vivendo" (G., $6^{\circ}$ a.), "diz sobre isolamento e sobre não ter mais sentido na vida" (A., $7^{\circ}$ a.). "Fala do homem estar só, longe de toda tecnologia moderna, num mundo onde quem tem a liberdade são os animais" (K., $4^{\circ}$ a.), "que sem internet nós percebemos o que está a nossa volta" (F., $5^{\circ}$ a.). Ponderamos que, embora ambas as entradas apontem a outros horizontes, elas também tangenciam a solidão e a circunstância de estar sozinho.

\section{b) Sensações e modos de sentir}

Ao questionarmos quais sensações e modos de sentir ${ }^{8}$ as ilustrações produzem, recebemos respostas como: "eu sinto a tristeza subindo" (M., $5^{\circ} \mathrm{a}$.), "sentimento de dúvida" (P., $2^{\circ} \mathrm{a}$.), "sentimento de confusão" (J., 6 ${ }^{\circ}$ a.), "confuso" (M., 5ª.), "sentimento de bem-estar" (K., 7ª.), "sensação de tranquilidade" (G., $8^{\circ}$ a.), "contemplação" (H., 5ª.), "paz e solidão" (A., $8^{\circ}$ a.), "[sensações] de cuidado com os seres e coisas" (E., $8^{\circ}$ a.), "agonia" (B., $9^{\circ}$ a.). Exibimos nesse arranjo uma amostra da miríade de possibilidades díspares que as produções movimentam.

Atenta-se, no entanto, a um tipo de asserção que sobressalta: "ele está em um lugar lindo mas está em um canto triste" (P., $7^{\circ}$ a.), "há um sentimento de tristeza por ver ela isolada em lugares tão bonitos" (G., $9^{\circ}$ a.). Essas falas associam vertentes que são compostas de maneira bifurcada: lindotriste, tristeza-tão bonitos. Uma aluna e um aluno relatam, mais precisamente, um "sentimento de alegria e tristeza" (L., $6^{\circ}$ a., A., $5^{\circ}$ a.). Não se trata, portanto, de uma coisa ou de outra, mas de ambas juntas, operando em uma só vez, em um só tempo, ainda que sejam diferentes ou opostas.

Listamos mais afirmativas nessa trilha: "[o conjunto das obras] me passa um sentimento misturado" (C., $2^{\circ}$ a.), "a tristeza de estar sozinha e a calmaria de estar em silêncio. São sentimentos misturados" (S., $9^{\circ} \mathrm{a}$.), "triste, solitário, pensativo, misturado bom e ruim" (E., $1^{\circ} \mathrm{a}$.), "sentimentos misturados, bons e confusos" (V., $3^{\circ} \mathrm{a}$.). Depreendem-se dessas falas certas sensações e determinados modos de sentir que são acompanhados de outras sensações e de outros modos de sentir, produzindo, assim, alianças e enredando uma cadeia; trata-se de uma coisa e outra e talvez mais outra.

Composições como essas, que somam elementos, são abordadas por Deleuze (DELEUZE; PARNET, 1998) e por Deleuze e Guattari (2011) pela perspectiva de rizoma, termo que vem da botânica referente ao crescimento da base de plantas, sem hierarquia ou ordenação, ou seja, pelo meio. "A árvore é filiação, mas o rizoma é aliança, unicamente aliança. A árvore impõe o verbo 'ser', mas o rizoma tem como tecido a conjunção 'e... e... e..."' (DELEUZE; GUATTARI, 2011, p. 48). Essa mirada interessa a nossa proposta tanto pela possibilidade de fazer conexões como pelo ângulo do que se passa 'entre', tendo em vista os encontros de forças dos alunos e das obras.

Deleuze defende que o pensamento faça ligações, mas também fusões, aliando-se ao que o fomenta, o confronta, o instiga e o dispara. Dessa forma, pode-se perfazer o que o filósofo francês chama de violência com o pensamento, que consiste em insistir em desdobrá-lo, levando-o ao limite. Pela perspectiva deleuziana, o ato de pensar não se restringe a fechamentos predeterminados. Ele se faz nesses enfrentamentos e em articulações que deslizam de uma ideia a outra. Com isso, Deleuze trata da necessidade de minimizarmos o perseverante acento no "é"

\footnotetext{
${ }^{8}$ Tomamos sensações e modos de sentir como indicadores de atravessamentos pelos quais se passa e que envolvem os sentidos. Ao serem articulados aqui como efeitos, não nos interessa defini-los separadamente, mas arrematá-los unidos.
} 
em favor de um deslocamento ao "e" "não no sentido de uma relação particular e puramente conjuntiva, mas no sentido de toda uma série de relações. $O$ 'e' é atribuído à possibilidade de criação, à gagueira criadora, à multiplicidade" (DOSSE, 2010, p. 18). Ou seja, em vez de insistir em classificar o que uma coisa é, pode-se vazar essa ânsia de delimitar e, no lugar de perseguir unidades bem definidas, focalizar nuances.

As alianças firmadas pelos alunos consistem em uma montagem da maior importância na medida em que congregam uma multiplicidade em operação. Ressaltamos que eles as apontam sem se deterem em determinações restritivas, já conhecidas ou preestabelecidas; asseveram, assim, que algo alegre pode ser também triste e vice-versa, transbordando possibilidades. Alegar que a ambiência do conjunto das obras traz sensações e modos de sentir alegres e tristes ao mesmo tempo, por conseguinte, conjectura uma complexidade do que se passa nesse território, tal como uma aluna nos traz: "parecem imagens tristes sorrindo para nós porque você acha que não tem muito desenho, mas tem. O menino acha que está só mas se olhar com outros olhos tem mais do que ele pensa ali" (L., $6^{\circ}$ a.).

\section{c) Percursos de pensamentos e modos de sentir}

Mirando outro aspecto, elencamos mais respostas acerca do que o conjunto das ilustrações dá a pensar. "Me faz pensar que a gente não pode viver na tristeza" (P., $5^{\circ}$ a.), "coisas inimagináveis que nós humanos nem sabemos que existem" (M., $4^{\circ} \mathrm{a}$.), "que as pessoas não veem mais o mundo ao redor" (M., $5^{\circ}$ a.), "que no mundo existem muito mais coisas além daqui" (P., $5^{\circ}$ a.), "que se formos ver o todo, o nosso problema passa a ser muito pequeno" (V., $5^{\circ} \mathrm{a}$.). Notam-se, nessas proposições, arremessos de maior vulto quanto a ultrapassagens de determinados limites, como esta aluna que traça paralelos, fazendo aproximações: "quando ela está no oceano ou entre as aves parece que ela está num quarto fechado" (G., $4^{\circ} \mathrm{a}$.).

Em muitas produções textuais, como as citadas acima, podemos vislumbrar percursos de pensamento. Endossamos essa sustentação conforme a perspectiva deleuziana do ato de pensar. Ao serem inseridos na ambiência que se arma com as quatro obras, os alunos participantes tiveram de enfrentá-la para, depois, lidar com as provocações. Nesse território que se formou, foram impelidos a se imiscuírem às ilustrações, pois, como forças, entraram em contato com as obras, que são outras forças. Como muitas dessas produções apontam a deslocamentos e movências, efetuados a partir das experimentações, cotejamos, por esse confronto e por essa insistência presentes, que há aí percursos de pensamento pela perspectiva deleuziana. Inclusive, é nesse sentido que apontamos arremessos de maior vulto.

Nesse enfrentamento, alguns alunos vasculham o próprio ato de pensar, conforme anuncia uma aluna: "essas imagens me fazem perceber que quando paramos para pensar em algo e nos concentramos muito, o mundo ao nosso redor parece que para. Mas, na verdade, ele continua com seus afazeres inúmeros e corridos, nós que não prestamos mais atenção" (A., $7^{\circ} \mathrm{a}$.). Evidencia-se nessa proposição um pensamento que leva a outro lugar, que proporciona um deslocamento. E a insistência no ato de pensar sobressai quando a aluna se refere a concentrarse muito, o que remete a perseverar nessa ação.

Esse enfrentamento também foi encarado em tentativas de abarcar e apreender como as coisas se passam na ambiência das obras. A mesma aluna declara: "a personagem precisa parar pra entender como tudo isso aconteceu" (A., $7^{\circ}$ a.). Outros participantes, respondendo ao que as obras dão a pensar, afirmam: "que isso de tudo acontecer é verdade" (V., $\left.5^{\circ} \mathrm{a}.\right)$, "uma menina que pensa que não tem nada de divertido ou impressionante para fazer, mas ao redor dela tem diversidades de coisas para fazer que ela ignora sem perceber" (G., $9^{\circ}$ a.), "[as obras fazem pensar] que existe um mundo inteiro no céu, no mar, no espaço e até mesmo aqui na terra. Isso nos diz que o quê a gente 
sabe é só a pontinha de um grande iceberg. E que há muito para aprendermos" (Y., $7^{\circ} \mathrm{a}$.), "[as obras fazem pensar na] vasta dificuldade de entendimento do mundo. A gente não tem o mínimo de noção do que se passa em volta da gente" (F., $9^{\circ}$ a.), "o menino se vê sozinho mas não vê o que está de verdade em volta dele" (G., $6^{\circ}$ a.), "[as imagens] me fazem pensar em uma pessoa que só fica presa ao que ela conhece e ao que a faz confortável" (S., $9^{\circ}$ a.).

Ainda nessa trilha, a disposição de um confronto também surge de modo mais aguçado e, ao mesmo tempo, sensível, como efeito do contato com as obras. A mesma aluna que declarou "eu sinto a tristeza subindo", acresce: "assim que as pessoas veem a tristeza não tem como escapar dela" (M., $5^{\circ}$ a.). Outro participante também pontua: "tristeza é inevitável. Achei interessante, pensei que não vale a pena virar as costas para o mundo, algumas vezes me senti dentro das imagens" (A. $4^{\circ}$ a.).

Por outra provocação, observam-se embates que dois alunos participantes travam diante dessa ambiência, ao responderem o que diriam ao personagem das ilustrações. "Se anima, cara, olhe tudo ao seu redor, olhe o mundo. Nós somos tão abençoados que nós não damos valor ao que temos e às vezes não enxergamos a beleza do mundo" (M., $4^{\circ}$ a.). "Quando você olha ao redor você pode pensar em coisas para te deixar feliz. Eu iria falar para ela não ficar triste pois existem coisas boas para se pensar" (E. $4^{\circ}$ a.).

Espraiam-se, nessa seleção de falas deste tópico, empreitadas de diversas ordens. Os alunos tratam de um não-saber e do fato de que se sabe muito pouco. Apontam a dificuldade de apreensão do mundo e de determinados acontecimentos, assim como de notar o que está ao redor. Abordam, inclusive, como se passa desapercebido ou mesmo se ignora o que ocorre em volta. Tais proposições carreiam enfrentamentos, mas não só; arrastam atravessamentos. Inferimos, desse modo, de acordo com essas produções, que parece ter havido contágios entre as forças nesses encontros, o que aproximamos da perspectiva deleuziana de afecções.

Deleuze (2002) propõe a perspectiva de afecções a partir de Espinosa. Ela trata de algo que ocorre ao mesmo tempo no corpo e na mente e tem mais intensidade do que afetos, do que afetar-se com algo. "Afecção remete a um estado do corpo afetado e implica a presença do corpo afetante" (DELEUZE, 2002, p. 56). Ao abordarmos esse encontro de forças entre alunos e obras, essa perspectiva refere-se ao efeito de um atravessamento que se tem e que perpassa o corpo e o pensamento, de forma sensível.

Posto isso, podemos afirmar - novamente e, agora, por outro âmbito - que a execução dessa atividade traz diversas falas que vão ao encontro do ato de pensar pela perspectiva deleuziana, uma ação que se vincula a uma dimensão sensível, já que, para Deleuze, pensar é algo que se faz com o corpo todo. Em síntese, a ação de pensar envolve um atravessamento com algo que é sentido.

Por essa via, em resposta à pergunta sobre o que a ambiência das obras dá a pensar, recebemos: "[ela] me fez pensar que ficar sozinho não é bom para ninguém e senti tristeza porque muitas pessoas são sozinhas" (L., $5^{\circ}$ a.), "coisas novas, descobertas. Senti que nós podemos apreciar o mundo de uma forma única" (H., $5^{\circ}$ a.). Na primeira frase, o aluno conjuga a ação de pensar pari passu à indicação de um modo de sentir. Ainda que o participante não se valha do sentido de pensar deleuziano, observa-se um esforço empreendido na proposição, assim como um viés sensível em jogo, sendo que ambos operam juntos, vinculados. Na segunda frase, a aluna poderia ter usado o verbo pensar, mas prefere a ele o verbo sentir. Com isso, também pode ser posto em relevo um viés sensível e um esforço empreendido.

$\mathrm{O}$ ato de pensar para Deleuze aproxima-se, portanto, da perspectiva de afecções. Pode-se sondá-la, ao esquadrinhar as falas, em uma indicação que se repete. Uma aluna nos traz: "gostei bastante de saber que eu não era a única a sentir isso" (H., $4^{\circ} \mathrm{a}$.). O mesmo aluno que indicou sensações de "paz e solidão" sobre a segunda provocação, explica: "não penso em uma solidão literalmente. É tipo uma solidão gostosa, não sei, só sei que gosto disso" (A., $8^{\circ} \mathrm{a}$.). Ora, sentir isso, o quê? E, de que se gosta, afinal? A dupla de participantes não define. Os termos 'isso' e 
'disso' remetem a modos de sentir que eles não nomeiam, o que nos faz supor que, talvez, sejam da ordem do incapturável, e, com isso, podem apenas ser sentidos. Eis aí afecções.

\section{d) Proposição de perguntas}

A terceira provocação que entoamos teve como disparador mais uma mirada deleuziana: a importância de criar os próprios problemas. Segundo o filósofo francês,

[...] o professor é quem "dá" os problemas, cabendo ao aluno a tarefa de descobrir-lhes a solução. Desse modo, somos mantidos numa espécie de escravidão. A verdadeira liberdade está em um poder de decisão, de constituição dos próprios problemas: esse poder, "semidivino", implica tanto o esvaecimento de falsos problemas quanto o surgimento criador de verdadeiros. (DELEUZE, 1999, p. 9)

Realça-se a questão de constituir os próprios problemas na medida em que ela também remete ao ato de pensar que, como visto, para Deleuze, é sinônimo de criar. Acreditamos que instigar a elaboração de perguntas pode ser uma maneira de fazer com que os alunos se movam. Isso porque elas podem consistir em uma oportunidade múltipla de proposição e de criação e incomodar, assim como reverberar o que disparam. E para trabalhar com produções deste tipo, fazemos coro a Yolanda Reyes no sentido de que "precisamos de histórias, de poemas e de toda literatura possível na escola não para sublinhar ideias principais (...)" (2012, p. 28), mas para instigar, criar movimentações, fomentar fluxos. Com efeito, precisamos da arte.

Tendo esse horizonte em vista e fazendo um mínimo aceno a tal possibilidade, interrogamos: "se as imagens fizessem uma pergunta, qual pergunta seria?". Listamos, a seguir, uma seleção do que os estudantes propõem. "Por que tantas tristezas? Há um mundo lá fora. As pessoas ficam tristes por motivo nenhum. Às vezes é tão simples ficar feliz. Talvez ele precise de amigos" (K., $5^{\circ}$ a.). "Viu como os papéis se inverteram?" (K., $4^{\circ} \mathrm{a}$.). "Você também está perdido?" (N., $8^{\circ}$ a.). "Por que virou de costas para o mundo?" (A., $5^{\circ}$ a.). "Por que o mundo é assim tão bonito?" (H., $5^{\circ}$ a.). "Você acha que a sua vida é um problema?" (R., $7^{\circ}$ a.). "Será que eu sou assim igual esse menino?" (L., $6^{\circ} \mathrm{a}$.). "Por que as pessoas são tão tristes se a natureza é tão bela?" (F., $9^{\circ}$ a.). "Por que para pensar em tudo que está acontecendo precisa estar sozinho?" (M., $6^{\circ}$ a.). Sobre essa última frase, o aluno se refere à questão pandêmica, conforme explica na íntegra da resposta que nos enviou.

Assim como as proposições anteriores, as respostas em formato de pergunta tangem modos de sentir, afecções e trajetórias de pensamento. Ao promover demandas a partir da ambiência das obras, essas produções, mostrando efeitos das forças em jogo, escancaram possibilidades de contato e contágios com as ilustrações, tal como estas perguntas provocativas que selecionamos para destacar por fim: "você está prestando atenção?" (M. 4ª.), "quais coisas apareceram na imagem?" (A., $8^{\circ}$ a.), "você consegue me ver?" (A., $7^{\circ}$ a.).

$* * * *$

Há alguns bastidores deste trabalho que merecem menção. As movimentações agitadas pelos alunos nos fizeram partilhá-las; assim, as apresentamos em uma mesa do III Colóquio Variações Deleuzianas: corpo entre Filosofia e Arte e Educação..., realizado via Google Meet, em 24 de novembro de $2020^{9}$, o que oportunizou a escrita deste artigo. Enfocando um viés mais

\footnotetext{
${ }^{9}$ Site do evento: https://variacoesdeleuze.wixsite.com/iicoloquio/?lang=pt.
} 
teórico da proposta - pela abordagem do operador conceitual que a move, qual seja, a perspectiva de afecções -, ela também foi levada ao VII Encontro GT Deleuze e Guattari pensar em veredas que se bifurcam: clínica, política, técnica, educação, arte, literatura -, realizado em 10 de dezembro de $2020^{10} 11$.

No mais, frisamos um fator fulcral à realização desta atividade: as aulas das disciplinas Sala de Leitura e Arte, que propiciam, no currículo escolar, aberturas como esta. As aulas de Sala de Leitura são oferecidas uma vez por semana (dentro de um esquema regular não pandêmico) e têm mediação de um professor de qualquer área de formação, designado sob o nome de POSL - Professor Orientador de Sala de Leitura, que também é responsável pela organização do acervo de livros da escola. O POSL media leituras, apresentando possibilidades múltiplas de fruição desvinculadas de avaliação, nota e métricas objetivas de rendimento.

Tendo em vista o contexto pandêmico, assim como o encontro entre literatura e jovens leitores, foi estabelecida, em 2020, a parceria da disciplina Sala de Leitura com a de Arte, que também dialoga com aspectos mais subjetivos da formação dos estudantes. O potencial da união nos levou a apostar nesta atividade tal como Yolanda Reyes defende que seja feito um trabalho com a literatura, dando "vazão à imaginação dos alunos e ao livre exercício de sua sensibilidade, para impulsioná-los a ser recriadores dos textos" (2012, p. 27). Desse modo, no trabalho remoto, as professoras responsáveis partiram de um fazer coletivo interdisciplinar e democrático.

\section{Considerações finais}

Exibimos neste artigo a trajetória empreendida com a proposta de uma atividade em que, a partir de uma ambiência com quatro obras de arte, disparamos estímulos e recebemos como resposta produções bastante provocadoras. Após descrever a iniciativa, apresentamos um panorama de sua execução, acionando falas dos alunos, que organizamos em quatro tópicos, e, com essa disposição, tecemos algumas análises.

Ao expor tal mostra de produções textuais, que consistem em dados que obtivemos, demos visibilidade aos encontros, contatos e contágios entre os alunos e as obras do quadrinista Rafael Sica. Para tanto, procuramos incitá-los, intentando conectar os participantes àquilo que poderia despontar, ao que poderia vir a ser desdobrado, ao imponderável desses encontros. Vislumbram-se nessas falas rastros de experimentações que podem levar o pensamento ao limite, a pensar mais e mais - em enfrentamentos -, e que tratam de um atravessamento sensível, que tomam corpo e pensamento de uma só vez.

A despeito das adversidades causadas pela circunstância pandêmica à educação - sendo que algumas delas parecem insuperáveis em um país desigual como o Brasil -, é preciso desviar o olhar às possibilidades que se deram para conseguirmos respirar um pouco em tempos tenebrosos. Expusemos aqui uma tentativa nesse sentido: em meio a um movimento de transmutação da desafiadora realidade imposta, uma oportunidade de vazar modos de sentir e de insistir no ato de pensar pelo contato e confronto com um conjunto de obras de arte.

\section{Referências}

DELEUZE, Gilles. Bergsonismo. Trad. Luiz Orlandi. São Paulo: Editora 34, 1999.

10 Site do evento: http://www.deleuzeguattari.com/\#about, transmissões das mesas pelo You Tube: https://www.youtube.com/playlist?list=PLrU4lukqiYq2gXz8jAClwtuH6wQzaaIUi.

${ }^{11}$ Esta segunda apresentação propiciou um convite para a produção de outro artigo: Afecções, arte e educação: alunos da rede municipal de São Paulo em encontros com quatro ilustrações do quadrinista Rafael Sica (SILVA), no prelo, que será publicado na revista Aprender. 
DELEUZE, Gilles. Espinosa: filosofia prática. Trad. Daniel Lins e Fabien Pascal Lins. São Paulo: Escuta, 2002.

DELEUZE, Gilles. A imanência: uma vida... Educação \& realidade, Porto Alegre, v. 27, n. 2, jul.-dez. 2002a, p. 10-18. Disponível em: https://seer.ufrgs.br/educacaoerealidade/article/view/31079/19291/. Acesso em: 21/11/2020.

DELEUZE, Gilles; GUATTARI, Félix. O que é a filosofia? 3. ed. São Paulo: Editora 34, 2010.

DELEUZE, Gilles; GUATTARI, Félix. Mil platôs: capitalismo e esquizofrenia 2. Vol. 1. 2. ed. São Paulo: Editora 34, 2011.

DELEUZE, Gilles; GUATTARI, Félix. Mil platôs: capitalismo e esquizofrenia 2. Vol. 3. 2. ed. São Paulo: Editora 34, 2012.

DELEUZE, Gilles; PARNET, Claire. Diálogos. Trad. Eloisa Araújo Ribeiro. São Paulo: Editora Escuta, 1998.

DOSSE, François. Gilles Deleuze \& Félix Guattari: biografia cruzada. Porto Alegre: Artmed, 2010.

REYES, Yolanda. O lugar da literatura na educação. In: Ler e brincar, tecer e cantar literatura, escrita e educação. São Paulo: Pulo do Gato, 2012.

SICA, Rafael. Triste. São Paulo: Lote 42, 2019.

SILVA, Lilian dos Santos. Afecções, arte e educação: alunos da rede municipal de São Paulo em encontros com quatro ilustrações do quadrinista Rafael Sica. No prelo.

\section{Sobre as autoras}

Lilian dos Santos Silva é graduada em Comunicação Social - Jornalismo (Universidade Estadual Paulista, UNESP), tem Mestrado em Educação (Universidade Federal de São Paulo, UNIFESP) e é doutoranda em Educação (Universidade de São Paulo, FEUSP). É pesquisadora da Faculdade de Educação da Universidade de São Paulo. Tem experiência na área de comunicação, jornalismo e educação, com pesquisa nos seguintes temas: filosofia, literatura e Gilles Deleuze. É bolsista da CAPES.

E-mail: $\underline{\text { li1207@gmail.com. }}$

Lydia Minhoto Cintra. Universidade de São Paulo, São Paulo, São Paulo, Brasil.

E-mail: 1ydia.cintra@usp.br.

Glaucia Ribeiro Felipe Cabral. Universidade de São Paulo, São Paulo, São Paulo, Brasil. E-mail: glauciafelipe@ hotmail.com. 